Subscriber access provided by NATIONAL TAIWAN UNIV

Communication

\title{
First Examples of Organophosphorus-Containing Materials for Light-Emitting Diodes
}

Claire Fave, Ting-Yi Cho, Muriel Hissler, Chieh-Wei Chen, Tien-Yau Luh, Chung-Chih Wu, and Rgis Rau J. Am. Chem. Soc., 2003, 125 (31), 9254-9255• DOI: 10.1021/ja035155w • Publication Date (Web): 12 July 2003

Downloaded from http://pubs.acs.org on February 17, 2009

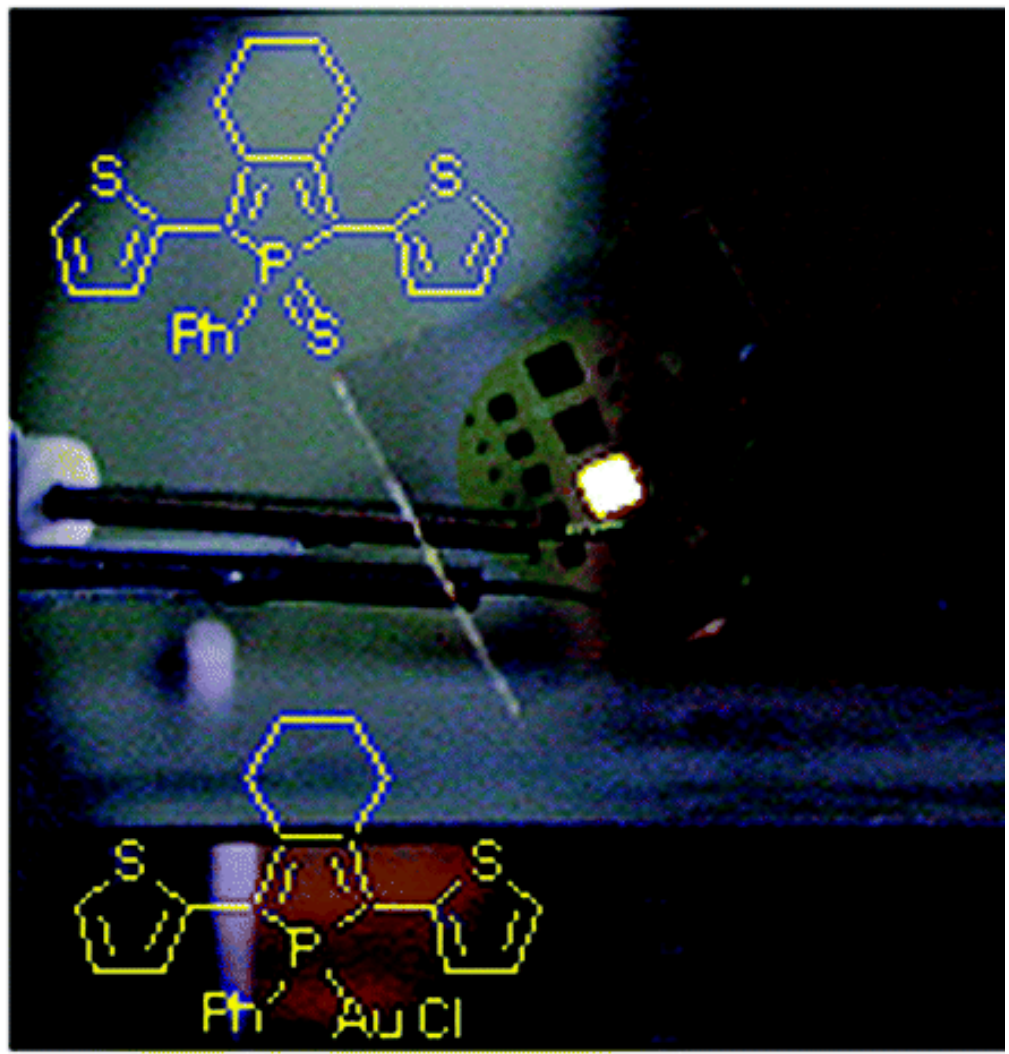

\section{More About This Article}

Additional resources and features associated with this article are available within the HTML version:

- $\quad$ Supporting Information

- $\quad$ Links to the 13 articles that cite this article, as of the time of this article download

- Access to high resolution figures

- $\quad$ Links to articles and content related to this article

\section{ACS Publications}


Subscriber access provided by NATIONAL TAIWAN UNIV

- Copyright permission to reproduce figures and/or text from this article

\section{View the Full Text HTML}

\section{ACS Publications}




\title{
First Examples of Organophosphorus-Containing Materials for Light-Emitting Diodes
}

\author{
Claire Fave, ${ }^{\dagger}$ Ting-Yi Cho, ${ }^{\ddagger}$ Muriel Hissler, ${ }^{\dagger}$ Chieh-Wei Chen, ${ }^{\ddagger}$ Tien-Yau Luh, ${ }^{\S}$ Chung-Chih Wu, ${ }^{, \neq}$and \\ Régis Reau*, \\ Institut de Chimie de Rennes, CNRS UMR 6509, Université de Rennes 1, Campus de Beaulieu, \\ 35042 Rennes Cedex, France, Department of Electrical Engineering, Graduate Institute of Electrooptical \\ Engineering and Graduate Institute of Electronics Engineering, National Taiwan University, Taipei, Taiwan 106, \\ and Institute of Chemistry, Academia Sinica, Taipei, Taiwan 115
}

Received March 14, 2003; E-mail: regis.reau@univ-rennes1.fr

Over the past decade, considerable effort has focused on the synthesis of organic $\pi$-conjugated systems for optoelectronic applications. ${ }^{1}$ One remarkable example is the development of small molecules or polymers for the preparation of organic light-emitting diodes (OLEDs), which represent a realistic alternative to the wellestablished liquid crystal devices used in flat-panel display technologies. ${ }^{1}$ Although monochromatic OLEDs are already used commercially, considerable advances are still to be made, especially toward full-color displays. ${ }^{1 \mathrm{~d}}$ Optimization of device performance is often tied to the use of new materials with readily tunable properties (thermal stability, redox potentials, emission wavelength, etc.).

We have recently shown that phospholes are versatile building blocks for the engineering of mixed $\pi$-conjugated oligomers such as $\mathbf{1}$ (Table 1). ${ }^{2}$ Chemoselective reactions involving the nucleophilic phosphorus center allow direct access to a range of new $\pi$-conjugated systems, without the need for additional multistep syntheses. Furthermore, these simple chemical modifications permit fine-tuning of the physical properties of phosphole-based $\pi$-conjugated systems. ${ }^{2 a, b}$ We now report that, by exploiting the reactivity of the phosphole core of derivative $\mathbf{1}$, access to the first organophosphoruscontaining OLED materials can be achieved.

The devices employed in this study have the typical structure of organic layers sandwiched between a bilayer anode and cathode (Table 2). ${ }^{3}$ The low-molecular-weight organic layers were deposited by thermal evaporation in high vacuum. This procedure led to the decomposition of phosphole 1 ; $^{2 \mathrm{a}}$ however, its thioxo-derivative $\mathbf{2}^{2 \mathrm{a}}$ (Table 1), which possesses a higher decomposition temperature, gave homogeneous thin films. The photoluminescence spectra (PL) of thin films of 2 showed a single maximum at $542 \mathrm{~nm}$ (Figure 1), a value close to that recorded in THF solution (Table 1). The OLED device A, containing a single layer of $\mathbf{2}$ (Table 2), exhibited yellow emission for a relatively low turn-on voltage of $2 \mathrm{~V}$. The electroluminescence spectrum (EL) of device A resembles the thin-film PL of 2, indicating similar mechanisms for both types of emission. The EL quantum efficiency is approximately constant up to high current (e.g., $600 \mathrm{~mA} \mathrm{~cm} \mathrm{~cm}^{-2}$ ), indicating a good operating endurability. ${ }^{4 a}$ However, the maximum brightness and EL quantum yields (Table 2) are low, presumably due to unbalanced carrier injection or transport. Therefore, a more advanced device $\mathbf{B}$, in which $\mathbf{2}$ was sandwiched between the hole-transport layer $\alpha-N P D$ and the electron-transport layer $\mathrm{Alq}_{3}$, ${ }^{1 \mathrm{a}, \mathrm{c}}$ was prepared. Comparison of the EL of device $\mathbf{B}$ with that of a reference device $\mathbf{G}$ (Table 2) suggests that its emission arises purely from $\mathbf{2}$ (Figure 1). Very interestingly, as compared to device $\mathbf{A}$, the turn-on voltage required to drive

\footnotetext{
† Université de Rennes 1.

\# National Taiwan University.

$\$$ Academia Sinica.
}

Table 1. Photophysical Data for Derivatives $1,2,{ }^{2 b}$ and 3

\begin{tabular}{|c|c|c|c|c|c|c|c|}
\hline & $\begin{array}{l}\mathrm{Td}_{10^{a}} \\
{\left[{ }^{\circ} \mathrm{C}\right]}\end{array}$ & $\begin{array}{c}\lambda_{\max }^{b} \\
{[\mathrm{~nm}]}\end{array}$ & $\log \epsilon$ & $\begin{array}{l}\lambda_{\text {em }}{ }^{b} \\
{[n m]}\end{array}$ & $\begin{array}{c}\phi_{f}^{b} \\
\times 10^{2}\end{array}$ & $\begin{array}{c}\mathrm{Epa}^{\mathrm{c}} \\
{[\mathrm{V}]}\end{array}$ & $\begin{array}{c}\mathrm{Epc}^{\mathrm{C}} \\
{[\mathrm{V}]}\end{array}$ \\
\hline 1 & 205 & 412 & 3.93 & 501 & 5.0 & +0.40 & $<-2.10$ \\
\hline 2 & 253 & 432 & 3.98 & 548 & 4.6 & +0.68 & -1.95 \\
\hline 3 & 218 & 428 & 4.18 & 544 & 14.0 & +0.82 & -1.75 \\
\hline
\end{tabular}

${ }^{a}$ TGA, $10 \%$ weight loss. ${ }^{b}$ Measured in THF; fluorescence quantum yield relative to fluorescein. ${ }^{c}$ In $\mathrm{CH}_{2} \mathrm{Cl}_{2}$, referenced to $\mathrm{Fc} / \mathrm{Fc}^{+}$half cell.

device $\mathbf{B}$ is almost unchanged, while the EL quantum efficiency and brightness are increased by nearly 1 order of magnitude.

Another effective way to further improve OLED performance, and also to tune their color, is to dope highly fluorescent dyes as guests into an emissive host matrix. ${ }^{1,5}$ Thioxophosphole $\mathbf{2}$ was thus evaluated as a host material for DCJTB, a popular pyran-containing red-emitting dopant for OLEDs. ${ }^{5 b}$ Device $\mathbf{C}$, which has a configuration related to that of device $\mathbf{B}$ except for a $1.4 \mathrm{wt} \%$ doping concentration in the organic layer of $\mathbf{2}$ (Table 2), showed red emission from DCJTB (Figure 1). This indicates effective resonant energy transfer or carrier trapping from 2 to DCJTB. Upon doping with DCJTB, the EL efficiency is further enhanced up to $1.83 \%$ photon/electron with a maximal brightness of ca. $37000 \mathrm{~cd} / \mathrm{m}^{2}$ (devices $\mathbf{B}$ and $\mathbf{C}$, Table 2). Of particular interest for practical applications, the EL quantum efficiency of phosphole-containing device C does not decrease with the driving current. ${ }^{4 a}$ This is an important improvement of the conventional DCJTB-doped $\mathrm{Alq}_{3}$ device $\mathbf{H}$ (Table 2), of which EL efficiency drops rapidly with the driving current, a common occurrence for this type of device due to the quenching effect of charged excited states of $\mathrm{Alq}_{3}$ on red dopants. ${ }^{5 \mathrm{~d}}$

To the best of our knowledge, these results give the first examples of OLEDs based on $\pi$-organophosphorus materials. This study raises interesting opportunities because the performance of these phosphole-based devices may well be further enhanced by tailoring the P-ring substituents. In this respect, because phospholes act as ligands toward metals, ${ }^{6}$ a less classical approach was envisaged whereby metal complexes are investigated as materials for OLEDs. ${ }^{7,8}$ In a preliminary study, $\mathrm{d}^{10} \mathrm{Au}(\mathrm{I})$ complexes were explored because they generally exhibit interesting luminescent properties in the solid state. ${ }^{8}$ Derivative $\mathbf{1}$ reacted with $\mathrm{ClAu}$ (tetrahydrothiophene) to afford complex $\mathbf{3}$ (Table 1), which was isolated as an air-stable orange powder in $84 \%$ yield. The downfield ${ }^{31} \mathrm{P}$ NMR coordination shift $(\Delta \delta, 26.3 \mathrm{ppm})$ clearly establishes coordination of the P-atom to the gold center. ${ }^{9}$ The simplicity of 
Table 2. Electroluminescence Characteristics of Devices $\mathbf{A}-\mathbf{H}$

\begin{tabular}{|c|c|c|c|c|c|c|c|c|c|c|c|}
\hline device & organic layer $(n m)^{a}$ & $\lambda_{\max } \mathrm{EL}^{\mathrm{L}}[\mathrm{nm}]$ & $V_{\text {on }}{ }^{[}[V]$ & $V_{20}{ }^{d}[\mathrm{~V}]$ & $V_{\max }{ }^{e}[\mathrm{~V}]$ & $B_{20}{ }^{\dagger} \mathrm{cd} \mathrm{m} \mathrm{m}^{-2}$ & $B_{\max }{ }^{9} \mathrm{~cd} \mathrm{~m}{ }^{-2}$ & $\eta_{20^{h}}$ & $\eta_{\text {max }}{ }^{i}$ & $\mathrm{Im} / W_{20}{ }^{j}$ & $I \mathrm{~m} / W_{\max }{ }^{k}$ \\
\hline $\mathbf{A}$ & compound 2(75) & 557 & 2.0 & 4.5 & 8.0 & 50 & 3613 & 0.09 & 0.16 & 0.175 & 0.222 \\
\hline B & $\alpha-\mathrm{NPD}(40) / 2(20) / \mathrm{Alq}_{3}(40)$ & 550 & 2.2 & 8.5 & 15.0 & 450 & 37830 & 0.74 & 0.80 & 0.827 & 1.14 \\
\hline C & $\alpha-\operatorname{NPD}(40) / \mathbf{2}: \operatorname{DCJTB}(20) / \mathrm{Alq}_{3}(40)^{b}$ & 617 & 2.4 & 8.0 & 13.5 & 530 & 36538 & 1.83 & 1.83 & 1.12 & 1.61 \\
\hline D & compound $\mathbf{3}(56)$ & 565 & 4.0 & 7.8 & & 0.15 & 2.6 & $3.7 \times 10^{-4}$ & $2.7 \times 10^{-3}$ & $3 \times 10^{-4}$ & $1.7 \times 10^{-3}$ \\
\hline $\mathbf{E}$ & $\alpha-\mathrm{NPD}(40) / \mathbf{3}(20) / \mathrm{Alq}_{3}(40)$ & 540 & 2.2 & 10.0 & 16.0 & 180 & 6575 & 0.35 & 0.36 & 0.28 & 0.39 \\
\hline $\mathbf{F}$ & $\alpha-\operatorname{NPD}(40) / 3: \operatorname{DCJTB}(20) / \mathrm{Alq}_{3}(40)^{b}$ & 623 & 2.2 & 10.5 & 15.5 & 200 & 2786 & 0.67 & 1.22 & 0.30 & 1.02 \\
\hline G & $\alpha-\mathrm{NPD}(40) / \mathrm{Alq}_{3}(60)$ & 530 & 2.2 & 8.8 & 15.5 & 900 & 68880 & 1.46 & 1.52 & 1.62 & 2.07 \\
\hline $\mathbf{H}$ & $\alpha-\operatorname{NPD}(40) / \operatorname{Alq}: \operatorname{DCJTB}(20) / \mathrm{Alq}_{3}(40)^{b}$ & 613 & 2.2 & 8.6 & 15.0 & 780 & 50719 & 2.20 & 3.70 & 1.40 & 6.0 \\
\hline
\end{tabular}

${ }^{a}$ Device configurations (thickness): ITO/PEDOT:PSS(25 nm)/organic layer/Mg: $\operatorname{Ag}(80 \mathrm{~nm}) / \operatorname{Ag}(150 \mathrm{~nm}) .{ }^{b} \mathrm{DCJTB} 1.4$ wt $\%$. ${ }^{c}$ Turn-on voltage at which emission becomes detectable $\left(\sim 10^{-4} \mathrm{~cd} \mathrm{~m}^{2}\right) .{ }^{d}$ Voltage for a current density of $20 \mathrm{~mA} \mathrm{~cm}{ }^{-2} .{ }^{e}$ Voltage at the maximum brightness (MB). ${ }^{f}$ Brightness at $V_{20}$. ${ }^{g}$ MB. ${ }^{h}$ External EL quantum efficiency (EELQ) at $20 \mathrm{~mA} \mathrm{~cm}{ }^{-2} .{ }^{i}$ Maximal EELQ. ${ }^{j}$ Luminous efficiency (LE) at $20 \mathrm{~mA} \mathrm{~cm}{ }^{-2} \cdot{ }^{k}$ Maximal LE.

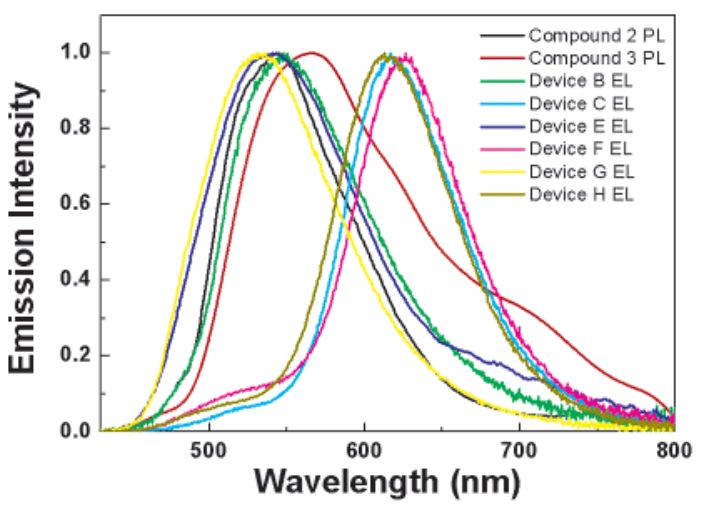

Figure 1. PL spectra of thin films of $\mathbf{2}$ and $\mathbf{3}$ and EL spectra of devices B-H.

the ${ }^{13} \mathrm{C}$ NMR spectrum favors a symmetric structure, discounting a chelating coordination mode of $\mathbf{1}$ involving a gold-sulfur interaction. ${ }^{4 \mathrm{~b}}$ These spectroscopic data fit perfectly with the solidstate structure of $\mathbf{3}$ established by an X-ray diffraction study. ${ }^{4 \mathrm{~b}}$ As expected, the $\sigma^{4}$-phosphorus atom adopts a tetrahedral shape, with the metal center in an almost linear geometry $[\mathrm{P}-\mathrm{Au}-\mathrm{Cl}, 174.6-$ $\left.(1)^{\circ}\right]$. It is noteworthy that the shortest $\mathrm{Au}(\mathrm{I})-\mathrm{Au}(\mathrm{I})$ distance in the solid state is $7.3 \AA$, indicating the absence of any aurophilic interactions. ${ }^{8}$ The optical data of $\mathbf{3}$ are very similar to those of $\mathbf{2}$ (Table 1), strongly suggesting that the absorption and emission of complex $\mathbf{3}$ in solution are associated with intraligand $\pi-\pi^{*}$ transitions. ${ }^{10}$ Interestingly, the quantum yield of $\mathbf{3}$ is 3 times as high as that of $\mathbf{2}$ (Table 1). The Epa and Epc of derivatives $\mathbf{2}$ and 3 differ noticeably (Table 1), a feature that may have an important impact on their electron-transporting properties. ${ }^{11}$

Complex $\mathbf{3}$ is thermally stable enough to give homogeneous thin films upon sublimation in high vacuum. The PL spectra of these thin films showed several maxima (Figure 1). The strong emission centered at $565 \mathrm{~nm}$ probably involves an intraligand $\pi-\pi^{*}$ transition, because this value is close to that recorded for $\mathbf{3}$ in THF solution (Table 1). The apparition of low energy emissions in the solid state is clearly associated with the presence of the $\mathrm{Au}(\mathrm{I})$ metal center, ${ }^{8}$ nicely illustrating the contribution of P-chemistry to the tuning of the optical properties of phosphole-based materials (Figure 1, derivatives $\mathbf{2} / \mathbf{3}$ ). Device $\mathbf{D}$ containing a single layer of complex 3 (Table 2) exhibited an EL emission resembling the PL of the thin film. The fact that the EL emission covers the 480-800 nm domain is encouraging for the development of white-emitting OLEDs based on phosphole-Au complexes. It is noteworthy that the EL performances can be considerably enhanced by adding charge-transporting layers or doping with DCJTB as well (Table 2, Figure 2, devices $\mathbf{E}, \mathbf{F})$. The fact that phosphole complexes can be used as materials for OLEDs expands considerably the potential of phosphole-based derivatives for further OLED developments.

In conclusion, we have given the first example of the use of organophosphorus $\pi$-conjugated oligomers for optoelectronic applications. $\pi$-Conjugated systems including organophosphorus moieties are still very rare; ${ }^{2,12}$ yet this work shows that the presence of reactive P-centers in these derivatives can offer new perspectives in the field of $\pi$-conjugated systems.

Acknowledgment. We thank the CNRS, the MENRT, the Conseil Régional de Bretagne (PRIR n 99CC10), and the National Science Council and Ministry of Education of R.O.C. for financial support.

Supporting Information Available: X-ray crystallographic data, analytical, spectroscopic data for 3, OLED device characteristics (PDF). This material is available free of charge via the Internet at http:// pubs.acs.org.

\section{References}

(1) (a) Kraft, A.; Grimsdale, A. C.; Holmes, A. B. Angew. Chem., Int. Ed. 1998, 37, 402. (b) Martin, R. E.; Diederich, F. Angew. Chem., Int. Ed. 1999, 38, 8, 1350. (c) Hung, L. S.; Chen, C. H. Mater. Sci. Eng., R 2002 39, 143. (d) Tullo, A. H. Chem. Eng. News 2001, 79, 49.

(2) (a) Hay, C.; Fischmeister, C.; Hissler, M.; Toupet, L.; Réau, R. Angew. Chem., Int. Ed. 2000, 10, 1812. (b) Hay, C.; Hissler, M.; Fischmeister, C.; Rault-Berthelot, J.; Toupet, L.; Nyulaszi, L.; Réau, R. Chem.-Eur. J. 2001, 7, 4222. (c) Fave, C.; Hissler, M.; Sénéchal, K.; Ledoux, I.; Zyss, J.; Réau, R. Chem. Commun. 2002, 1674.

(3) Wu, C.-C.; Chen, C.-W.; Lin, Y.-T.; Yu, H.-L.; Hsu, J.-H.; Luh, T.-Y. Appl. Phys. Lett. 2001, 79, 3023

(4) See the Supporting Information for (a) external EL quantum efficiency versus current for devices $\mathbf{A}, \mathbf{C}$, and $\mathbf{H}$; (b) spectroscopic, analytical, and crystallographic data of $\mathbf{3}$

(5) (a) Tang, C. W.; Vanslyke, S. A.; Chen, C. H. J. Appl. Phys. 1989, 65, 3610. (b) Chen, C. H.; Tang, C. W.; Shi, J.; Klubek, C. Macromol. Symp. 1997, 125, 49. (c) Roundhill, D. M.; Fackler, J. P. Optoelectronic Properties of Inorganic Compounds; Plenum Press: New York, 1999 (d) Young, R. H.; Tang, C. W.; Marchetti, A. P. Appl. Phys. Lett. 2002, 80,874 .

(6) (a) Mathey, F. Chem. Rev. 1988, 88, 429. (b) Quin, L. D.; Quin, G. S. In Phosphorus-Carbon Heterocyclic Chemistry: The Rise of a New Domain Mathey, F., Ed.; Elsevier Science Ltd.: Oxford, 2001.

(7) (a) Buda, M.; Kalyuzhny, G.; Bard, A. J. J. Am. Chem. Soc. 2002, 124 6090. (b) Rudmann, H.; Shimada, S.; Rubner, M. F. J. Am. Chem. Soc 2002, 124, 4918 and references therein.

(8) (a) Lee, Y.-A.; McGarrah, J. E.; Lachicotte, R. J.; Eisenberg, R. J. Am Chem. Soc. 2002, 124, 10663. (b) Yam, V. W. W.; Chang, C.-L.; Li, C.-K.; Wong, K. M.-C. Coord. Chem. Rev. 2001, 216-217, 173.

(9) (a) Attar, S.; Bearden, W. H.; Allcock, N. W.; Alyea, E. C.; Nelson, J. H. Inorg. Chem. 1990, 29, 425. (b) Gimeno, M. C.; Laguna, A. Chem. Rev 1997, 97,511

(10) Large Stokes shifts ( $>300 \mathrm{~nm}$ ) are generally observed for the triplet $\mathrm{Au}$ (I) center state: Ma, Y.; Zhou, X.; Shen, J.; Chao, H.-Y.; Che, C.-M Appl. Phys. Lett. 1999, 74, 1361 and ref 7.

(11) The redox processes likely involve the $\pi$-conjugated ligand and not the metal center because the Epa and Epc of (phosphane)AuCl complexes are generally much higher and lower than those observed with 3 respectively. For example, $\left(\mathrm{Ph}_{3} \mathrm{P}\right) \mathrm{AuCl}, \mathrm{Epc}=-2.4 \mathrm{~V}$, no oxidation peak appeared prior to $\mathrm{CH}_{2} \mathrm{Cl}_{2}$ discharge: Koelle, U.; Laguna, A. Inorg. Chim. Acta 1999, 290, 44.

(12) (a) Bevierre, M. O.; Mercier, F.; Ricard, L.; Mathey F. Angew. Chem. Int. Ed. Engl. 1990, 29, 655, (b) Deschamps, E- Ricard, L.: Mathey, F. Angew. Chem., Int. Ed. Engl. 1994, 11, 1158. (c) Mao, S. S. H.; Tilley, T. D. Macromolecules 1997, 30, 5566. (d) Wright, V. A.; Gates, D. P. Angew. Chem., Int. Ed. 2002, 41, 2389. (e) Lucht, B. L.; St. Onge, N. O. Chem. Commun. 2000, 2097. (f) Morisaki, Y.; Aiki, Y.; Chujo, Y Macromolecules 2003, 36, 2594. (g) Hissler, M.; Dyer, P.; Réau, R. Coord. Chem. Rev. 2003, in press.

JA035155W 